\title{
Application of a fatigue equivalent static load methodology for the numerical durability assessment of heavy vehicle structures
}

\author{
Johann Wannenburg ${ }^{\mathrm{a}, *}$, P. Stephan Heyns ${ }^{\mathrm{a}}$, Anton D. Raath ${ }^{\mathrm{b}}$ \\ a Department of Mechanical and Aeronautical Engineering, University of Pretoria, Pretoria, South Africa \\ ${ }^{\mathrm{b}}$ Consultants in Automated Test and Structural-Dynamic Simulation Systems (CaTs ${ }^{3}$ ) Ltd., Kenilworth, United Kingdom
}

\section{A R T I C L E I N F O}

\section{Article history:}

Received 18 July 2007

Received in revised form 27 April 2009

Accepted 30 April 2009

Available online $\mathrm{xxxx}$

\section{Keywords:}

Heavy vehicle

Structural

Durability

Design

Fatigue equivalent static loading

\begin{abstract}
A B S T R A C T
It is common practice in the automotive industry to employ multi-parameter strain-life methods, in combination with dynamic finite element analyses, based on very extensive measurement exercises, to conduct analytical fatigue life assessments, which is then verified through intensive durability testing. The expense and complexity of this approach makes its application impractical for low volume "special" vehicles. In this paper, a fatigue equivalent static load (FESL) methodology for the numerical durability assessment of heavy vehicle structures is presented, where fatigue load requirements are derived from measurements as quasi-static g-loads, the responses to which are considered as stress ranges applied a said number of times during the lifetime of the structure. The application of the method is demonstrated using two case studies, namely a road tanker and a load haul dumper. In both cases, it was possible to obtain adequately accurate fatigue life prediction results, using simplified loading, static finite element analyses and a stress-life approach to fatigue damage calculations, with material properties available in design codes.
\end{abstract}

(ㄷ) 2009 Elsevier Ltd. All rights reserved.

\section{Introduction}

The product development processes in the automotive and transport equipment industries are subject to ever higher demands on improved reliability, safety, and performance, as well as reduced weight, production cost and development lead times [1]. Huang et al. [2] report that less time is available for building and testing prototypes, therefore placing increasing emphasis on analytical durability assessment methods. In the case of special purpose vehicles, for which the low production volumes may exclude the possibility of extensive prototype testing, such emphasis would be even more pronounced.

The first step of any durability assessment process involves the definition of the loading conditions. The automotive industry is expending constant effort in correlating proving ground loading conditions with the customer profiles, or alternatively employs standardised load-time histories, also derived from extensive field measurements [3]. In the heavy vehicle industry and particularly for special vehicles, such information is not always readily available and the need for economical methods to describe loading conditions for design purposes, is apparent.

The second step of the assessment process involves the calculation of the stress response to the input loading. In the automotive

\footnotetext{
* Corresponding author. Tel.: +27 826520604; fax: +27 116382238.

E-mail address: jwannenburg@anglotechnical.co.za (J. Wannenburg).
}

industry, this is commonly achieved using dynamic finite element analysis methods, as described by Ryu et al. [4] and Huang et al. [2]. Due to the cost of dynamic finite element analyses there is an incentive to circumvent the need for such analysis. Such a simplified procedure is also required for design codes, since codes could not stipulate the use of dynamic finite element analysis methods, because this would restrict their usage to sophisticated users only.

Conle and Chu [5] state that in the automotive industry, the strain-life method is preferred for executing the final step of the durability assessment process, namely the calculation of fatigue damage. Since heavy vehicle structures are usually welded, the less complex stress-life method is however commonly employed.

It would therefore be common practice in the automotive industry to employ multi-parameter strain-life methods, in combination with dynamic finite element analyses, based on very extensive measurement exercises, to conduct analytical fatigue life assessments, which is then verified through intensive durability testing. The expense and complexity of this approach makes its application impractical for low volume "special" vehicles. In this paper, it is demonstrated for two non-trivial case-studies, that limited measurements, simple fatigue calculations (stress-life instead of strain-life) and static finite element analysis, can in such cases be employed to achieve adequately accurate fatigue life predictions. 


\section{The fatigue equivalent static loading methodology}

\subsection{Stress-life method}

The stress-life approach is described by Bannantine et al. [6]. The approach is based on the experimentally established material fatigue response curve, called the $S N$ curve, which plots the number of cycles $N$ or reversals $2 N$ to failure (mostly defined as the initiation of an observable crack) versus a nominal stress range $\Delta \sigma$ or amplitude $\sigma_{a}$.

For most metallic materials used in the vehicle and transport equipment industries, an approximate straight line may usually be observed on a log-log plot, resulting in a power-law relationship:

$\Delta \sigma=S_{f} N^{b}$

The fatigue coefficient $S_{f}$ and the fatigue exponent $b$ are material properties determined from curve fitting on experimental data.

The fatigue analysis of welded components, which is very important in vehicular structures, is based on original work done by Gurney [7]. SN curves, equivalent to the material properties used in the stress-life method, are derived from extensive tests performed on different weld joint specimens. Numerous fatigue design standards or codes are based on the above method, e.g. ECCS [8] and BS 8118 [9].

\subsection{Measurements}

In the derivation below, a heavy vehicle (considered to be typical in terms of weight, suspension, etc. of all vehicles in its class) is assumed to have been instrumented with strain gauges on its main chassis beams, measuring vertical bending stresses. Strain gauges are positioned to measure nominal stresses on a vehicle structure. Such gauges are placed away from stress concentration areas to ensure effects such as the slight misplacement of the gauge, the size of the strain gauges, as well finite element mesh refinement, do not influence the results.

The important assumption is made that the damage induced on the vehicle structure is dominated by the contribution of vertical loading.

The vehicle is assumed to have been driven on roads representative of normal usage for a distance of, say, $200 \mathrm{~km}$ whilst measurements were taken. It is important that the measured distance and terrain can be shown to be conservatively representative of "normal usage". In some cases, e.g. an industrial vehicle with a very typical and unchanging mission, measurements during one or two typical trips would suffice. In other cases a comprehensive statistical treatment would be required, such as described by Wannenburg [10].

\subsection{Measured damage calculation}

The measured stress-time histories are cycle-counted, using the range-pair-range algorithm provided in ASTM E 1049-85 [11], to yield a spectrum of stress ranges $\Delta \sigma_{i}$ and an associated number of counted cycles $n_{i}$. A relative fatigue damage (relative because generic material properties $b$ and $S_{f}$ are used) can be calculated using the stress-life approach. The exponent of the stress-life equation is chosen as -0.33 , being the gradient of almost all of the $S N$ curves in fatigue design codes, whilst the value of $S_{f}$ is arbitrary, since it will cancel out in the calculation.

Firstly, the number of cycles to failure at each stress range can be calculated by rearranging Eq. (1):

$N_{i}=\left(\frac{\Delta \sigma_{i}}{S_{f}}\right)^{1 / b}$
Then the total damage is calculated using the damage accumulation theory of Miner [12]:

Damage $=\sum \frac{n_{i}}{N_{i}}=\sum \frac{n_{i}}{\left(\frac{\Delta \sigma_{i}}{S_{f}}\right)^{1 / b}}$

\subsection{Equivalent stress range calculation}

The purpose then would be to obtain an equivalent bending stress range which would, when repeated an arbitrary $n_{e}$ times, cause the same damage to the beam to what would be caused during the total life (e.g. 1 million $\mathrm{km}$ ) of the vehicle, made out of repetitions of the measured trip. This damage could be calculated as follows:

$$
\begin{aligned}
& N_{e}=\left(\frac{\Delta \sigma_{e}}{S_{f}}\right)^{1 / b} \\
& \text { Damage }_{e}=\frac{n_{e}}{N_{e}}=\frac{n_{e}}{\left(\frac{\Delta \sigma_{e}}{S_{f}}\right)^{1 / b}}
\end{aligned}
$$

$\Delta \sigma_{e}$ can be solved by equating:

Damage $_{e}=$ Damage $\times 1$ million $\mathrm{km} / 200 \mathrm{~km}$

Therefore, combining Eqs. (3)-(5), substituting $m$ for $-1 / b=3$ and $n_{i}=$ cycles counted for each stress range from the total measured trip, multiplied by 1 million/200:

$$
\begin{gathered}
\sum \frac{n_{i}}{\left(\frac{\Delta \sigma_{i}}{S_{f}}\right)^{1 / b}}=\frac{n_{e}}{\left(\frac{\Delta \sigma_{e}}{S_{f}}\right)^{1 / b}} \\
\Delta \sigma_{e}=\left(\sum \frac{\Delta \sigma_{i}^{m} n_{i}}{n_{e}}\right)^{1 / m}
\end{gathered}
$$

An arbitrary choice of $n_{e}=2$ million is done because the fatigue classifications in many of the welding codes are denoted by the stress range values in MPa at 2 million cycles, for each $S N$ curve.

\subsection{Fatigue equivalent static loading calculation}

The bending stress $\sigma_{1 \mathrm{~g}}$, caused by $1 \mathrm{~g}$ (unit) vertical inertial loading at the strain gauge position, is then calculated using static finite element analysis.

The fatigue equivalent static loading (FESL), is then calculated as follows:

$\mathrm{FESL}=\frac{\Delta \sigma_{e}}{\sigma_{1 \mathrm{~g}}}$

This load is a single axis (vertical), inertial load range (i.e. peakto-peak), measured in $\mathrm{g}$, which, when applied 2 million times, would represent the fatigue loading of 1 million $\mathrm{km}$.

\subsection{Life assessment}

The FESL is then applied on the finite element model in a static analysis. The stresses thus calculated are interpreted as stress ranges, which would be repeated 2 million times during the life of 1 million $\mathrm{km}$. The fatigue life at each critical position may then be calculated, using the appropriate $S N$ curve relevant to the detail at each position.

The fatigue damage calculated at the strain gauge position (using the same $S N$ curve as for the measured damage calculation) would be equal to the measured damage, due to Eq. (5). It is then assumed that the operational dynamic stress responses at any other position on the structure, are proportional to the dynamic stresses at the strain gauge position by the same constant factor as the ratio between the vertical-static-inertial-load stress 
responses at the other positions and the strain gauge position. If this is the case, the fatigue damages calculated at the other positions would be the same as what would have been calculated from measured dynamic stresses at those positions.

In the application of the FESL method, it would therefore be good practice to place redundant (not used for FESL calculation) strain gauges on the structure. The measurements from the redundant gauges may then be used to calculate fatigue damages that may be compared to those calculated using the FESL. Close correlation would imply a high confidence level in the validity of the assumptions made.

\section{Application of FESL methodology on a road tanker vehicle}

\subsection{Problem definition}

A new dual purpose, aluminium road tanker was developed (see Fig. 1). The tanker features two trailers with flat decks to allow the transport of dry load cargo. This enables the operator to transport liquid loads in one direction and general freight on the decks during the return trip. The profitability of the vehicle is greatly improved.

The design presented challenges in terms of the box shaped design of the tanks, requiring significant internal reinforcing, and the use of aluminium to enhance the drive towards a lightweight design, implying concerns in terms of fatigue durability, as well as the uniqueness of the application, presenting the problem of determining the loading conditions.

\subsection{Methodology}

The durability assessment comprised the following steps:

- Finite element assisted design according to available design code prescribed loads.

- Building of prototype vehicle.

- Strain gauge measurements on prototype vehicle for typical operational cycles.

- Establishment of design criteria for fatigue loading.

- Redesign and extensive fatigue assessment using finite element and measurement results.

\subsection{Instrumentation and measurements}

After completion of the first prototype vehicle of the new design, comprehensive measurements were performed. Strain gauges and accelerometers were used. Strain gauges were placed to measure nominal stresses in as many areas required to reasonably characterise the stress response of the structure.

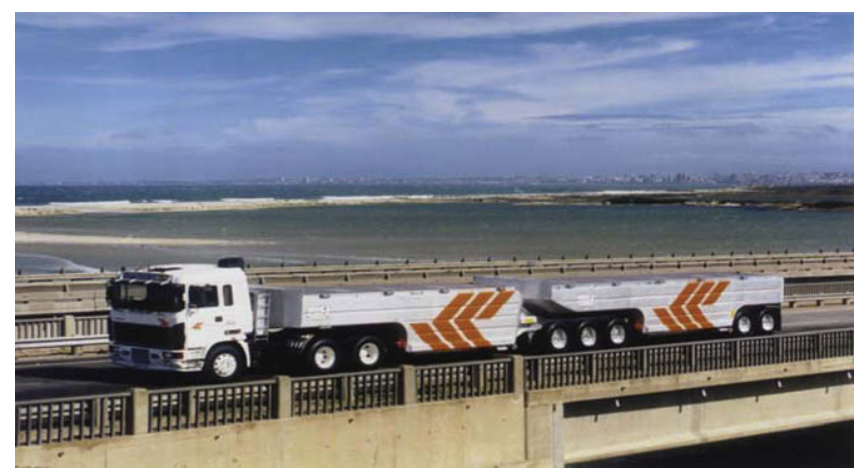

Fig. 1. Fuel tanker.

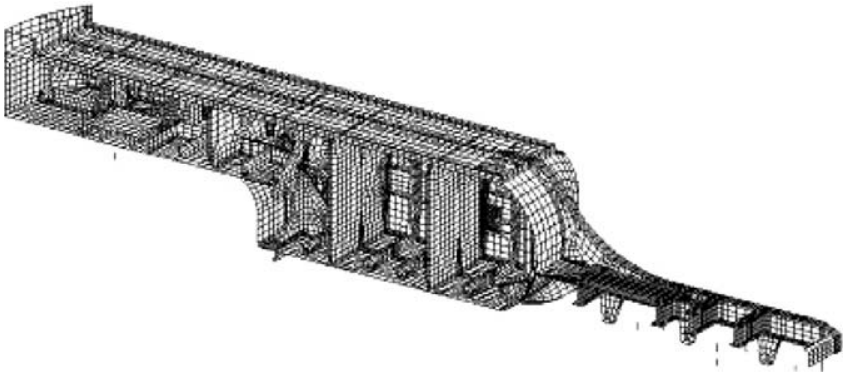

Fig. 2. Finite element model of fuel tanker front trailer.

The measurements included a typical $300 \mathrm{~km}$ trip with a liquid load, as well as a return empty trip.

\subsection{Finite element analysis}

Detailed finite element half models were constructed of the front and rear trailers, employing mainly shell elements. Own weight ( $1 \mathrm{~g}$ ) vertical inertial loading was applied. The liquid load was simulated using pressure loading. The front trailer model and results are depicted in Figs. 2 and 3, respectively.

The full description of the finite element model and the verification exercises conducted to ensure a valid model, are beyond the scope of this paper. Since the strain gauge measurement exercise results were employed to derive equivalent static loads (such that measured and calculated damages would correlate), measured dynamic stresses and equivalent static finite element stresses would not correlate. However, portions of the measurement results were used to verify the finite element analysis, such as the differences in measured stresses between the empty and full conditions.

\subsection{Measured damage calculation}

Fatigue damage calculations were performed on the measured data, using the process described in Section 2. A fatigue exponent of $b=-0.333$ was used.

\subsection{Fatigue equivalent static load calculation}

The bending stress measured by a strain gauge channel placed on the front trailer chassis flange at the position indicated in Fig. 3, was used for the FESL calculation, due to the fact that it is assumed that the vertically induced loads would represent most of the fatigue damage experienced on the vehicle structure. An equivalent stress range corresponding to 2 million cycles (arbitrarily chosen to correspond to the number of cycles at which the weld class is specified as discussed in Section 2), was calculated which would cause the same damage as would be caused at that channel for the measured trip extrapolated to a life distance of 2 million $\mathrm{km}$ (the fact that the life distance is equal to the chosen number of cycles is coincidental). Eq. (6) was again used for this purpose with $n_{i}$ =cycles counted for each stress range for the total trip, multiplied by 2 million/distance travelled during measurements. This was done on the assumption that a life of 2 million $\mathrm{km}$ would be expected of these vehicles.

The resultant equivalent stress range was found to be $15.5 \mathrm{MPa}$. The stress calculated by a finite element analysis for a $1 \mathrm{~g}$ load was $25 \mathrm{MPa}$. The equivalent vertical load therefore corresponds to a vertical acceleration of $15.5 / 25 \times 1 \mathrm{~g}=0.62 \mathrm{~g}$. It is then implied that any stress calculated in the vehicle structure at $0.62 \mathrm{~g}$ vertical loading would be repeated 2 million times during a life of 2 million $\mathrm{km}$. All welds should then be of a class higher than the nominal stress at the weld calculated for $0.62 \mathrm{~g}$ loading. According to BS 8118 , the class for a fillet weld would be 20 and for a butt weld 24 . 


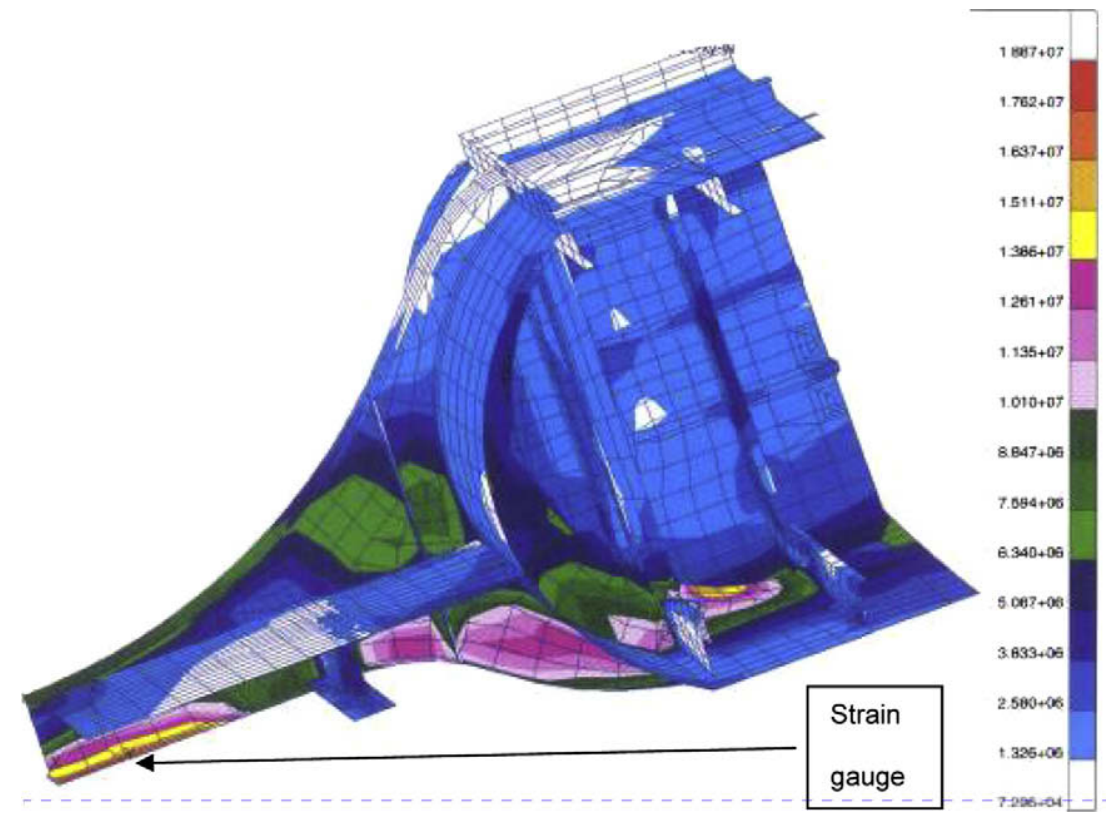

Fig. 3. Finite element results on fuel tanker front trailer.

Due to the fact that more than 30 strain gauges channels were recorded, the assumption that vertical loading contributes the major portion of the fatigue damage was extensively collaborated by comparing the FESL calculated fatigue damage at each strain gauge position, to the actual measured damages. In no case did these damages differ by more than $30 \%$.

\subsection{Fatigue life prediction of prototype design}

The fatigue design criteria derived above were subsequently used to estimate the fatigue life of the prototype design. It was found that acceptable lives were estimated for all critical areas, except for a bulkhead support beam of which the design therefore

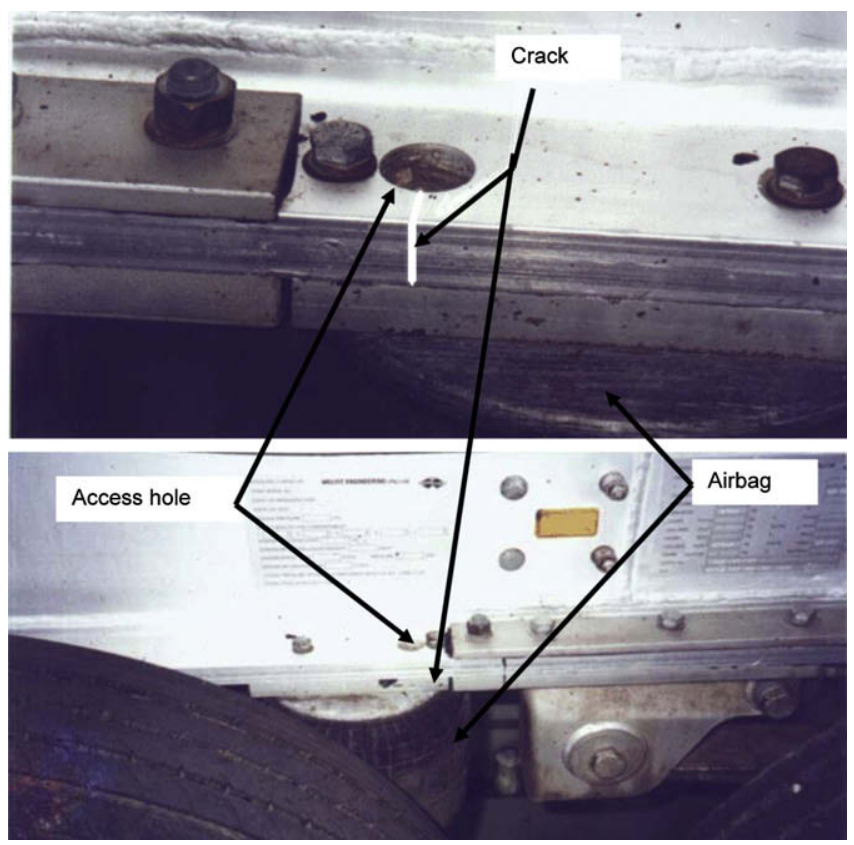

Fig. 4. Field failure on fuel tanker. had to be modified. It was therefore expected to have no failures during the required 2 million $\mathrm{km}$ vehicle lifespan. The majority of the vehicles in the fleet have to date exceeded the required life and in most cases no structural failures have been reported, thereby substantiating the FESL process. Premature field failures had been however reported on some vehicles. These failures were subsequently investigated and are described in the following Section.

\subsection{Field failure description}

The failures occurred on vehicles that were fitted with underslung axles, which were introduced due to availability problems with the overslung axles that were used in the original design. The engineering change procedure failed to highlight the fact that a large access hole (refer to Fig. 4) for the airbag was to be introduced on the inside of the lower flange of the chassis beam in a critical stress area. The cracks experienced in the field all originated from this hole (after typically $800000 \mathrm{~km}$ ) and in some cases propagated into the web to almost sever the beam.

\subsection{Prediction of field failures}

\subsubsection{Finite element analysis}

The complete half model of the front trailer was used for the analysis (refer to Fig. 2). The access hole was modelled and the mesh was refined in the critical area. Vertical inertial loading was applied.

The stresses at the hole for a $1 \mathrm{~g}$ vertical loading are depicted in Fig. 5. A maximum peak stress of $114 \mathrm{MPa}$ is observed at the side of the hole.

\subsubsection{Fatigue assessment}

The fatigue design criterion established above was that a fatigue life of 2 million $\mathrm{km}$ on the vehicle is represented by 2 million cycles of a vertical loading range of $0.62 \mathrm{~g}$. The fatigue equivalent peak stress range $\left(\Delta \sigma_{e}\right)$ at the side of the access hole, to be experienced 2 million times during a 2 million $\mathrm{km}$ life, would therefore be:

$$
\Delta \sigma_{e}=0.62 \times 114=71 \mathrm{MPa}
$$




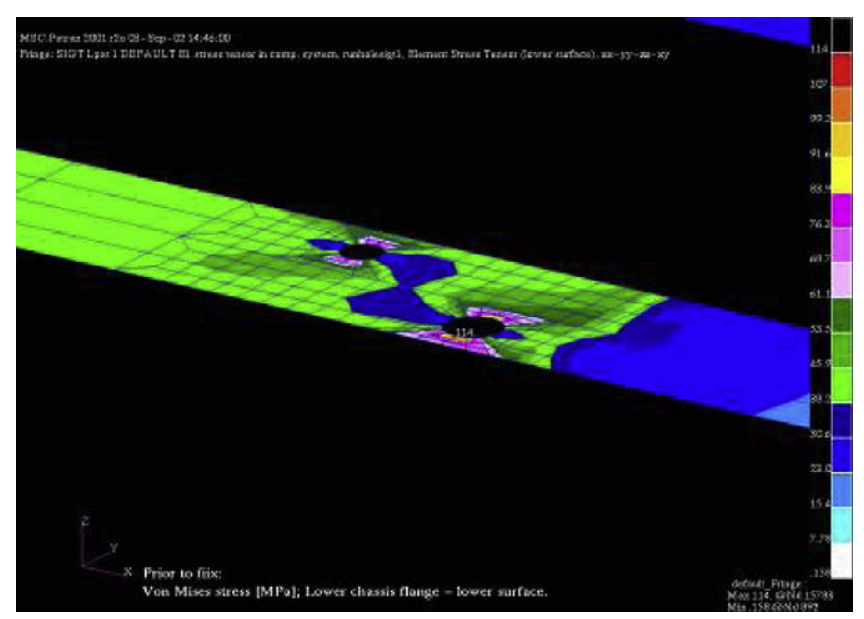

Fig. 5. Fuel tanker chassis flange stresses.

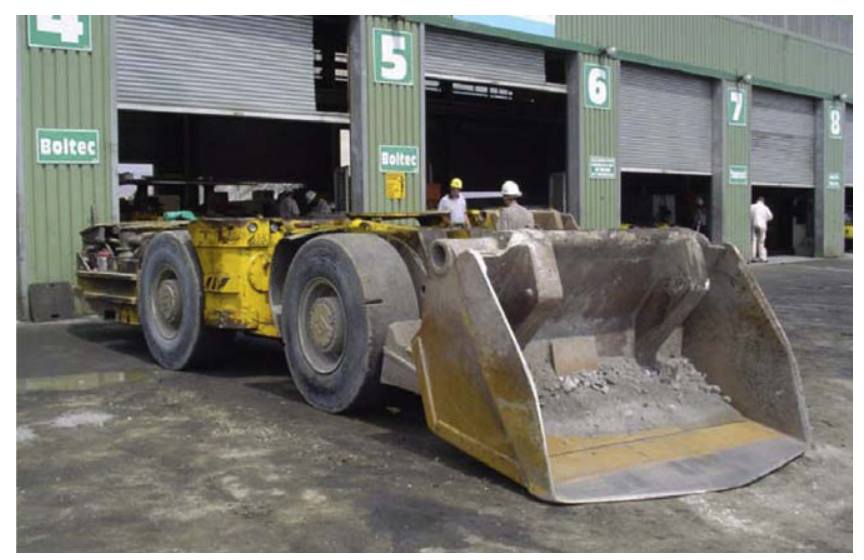

Fig. 6. Load haul dumper (LHD).
The material SN curve for unwelded Aluminum in BS 8118 has a class of 60 (2.3\% probability of failure), implying a fatigue strength (stress range) of $60 \mathrm{MPa}$ at 2 million cycles.

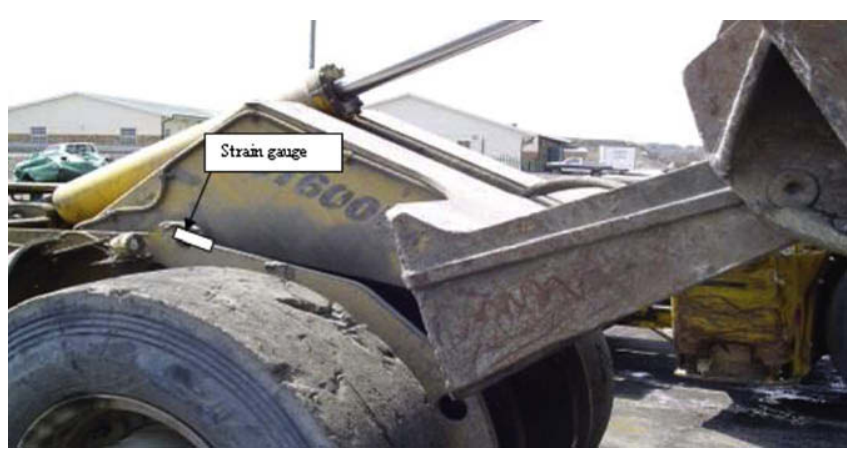

Fig. 7. Strain gauge position on boom (channel 3).

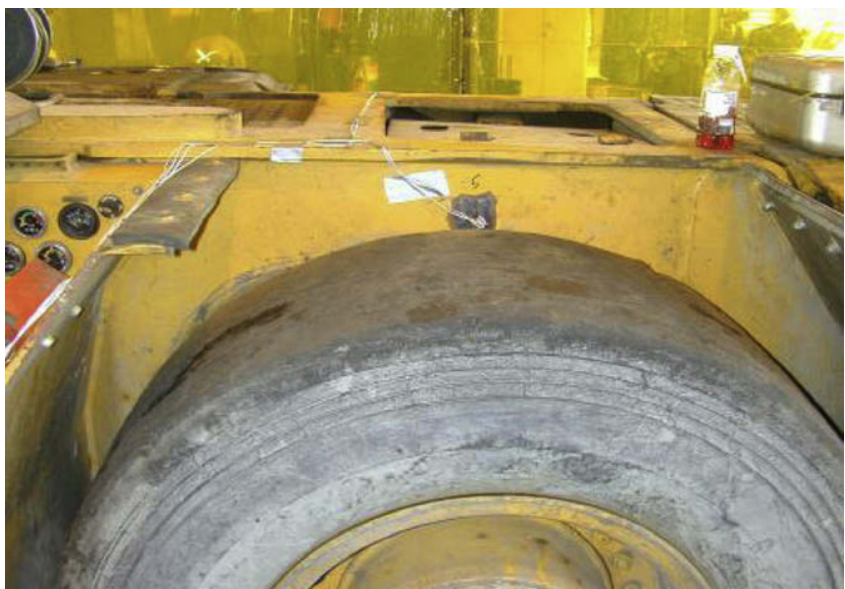

Fig. 8. Strain gauges above wheel-arch (channel 4).

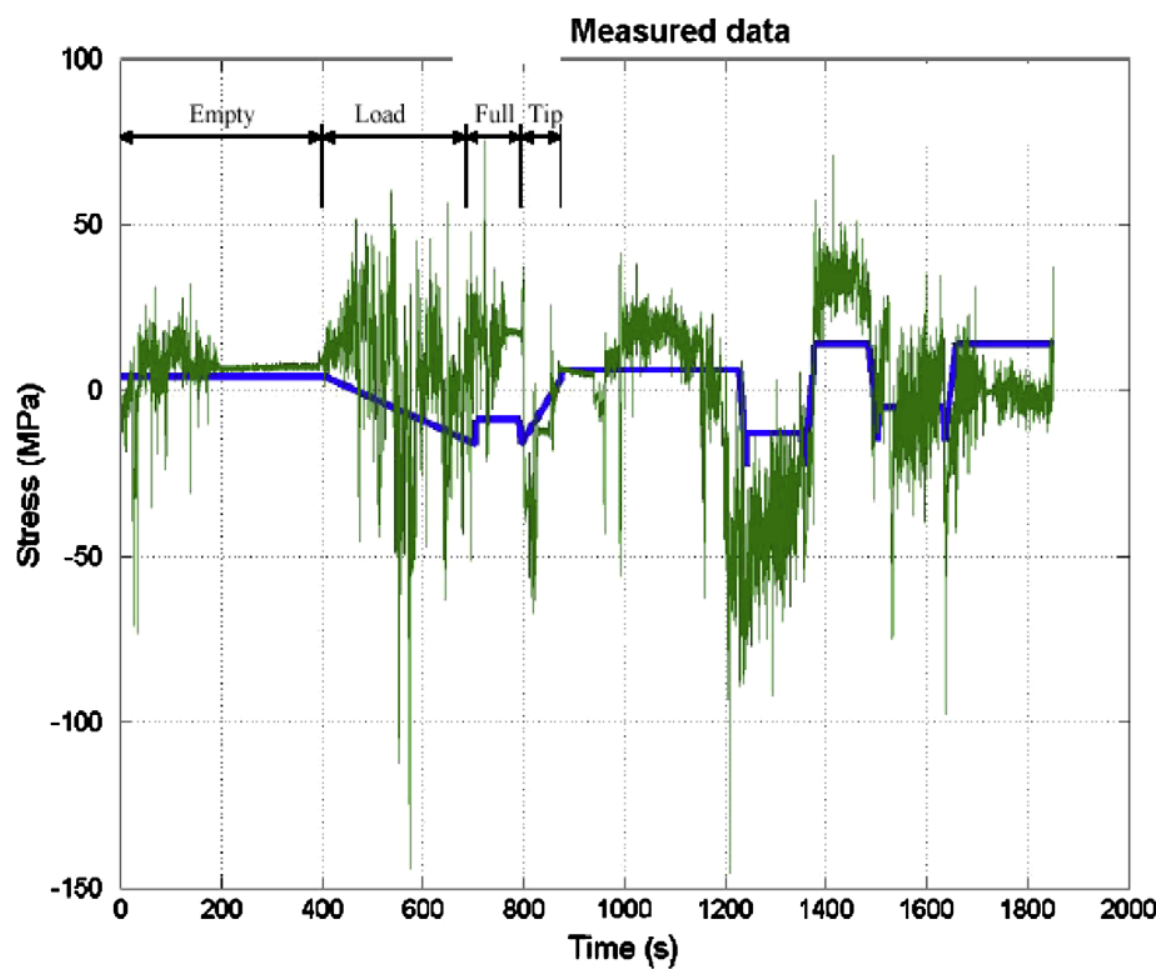

Fig. 9. Measurement results. 
The corresponding material fatigue properties as per Eq. (1) may be calculated as follows:

$$
\begin{aligned}
\Delta \sigma & =S_{f} N^{b} \\
b & =-0.333 \\
\therefore 60 & =S_{f}\left(2 \times 10^{6}\right)^{-0.333} \\
\therefore S_{f} & =7523 \mathrm{MPa}
\end{aligned}
$$

The life to failure implied by the $71 \mathrm{MPa}$ applied peak stress range can then be calculated:

$$
\begin{aligned}
\Delta \sigma & =S_{f} N^{b} \\
\therefore N & =\left(\frac{\Delta \sigma}{S_{f}}\right)^{1 / b} \\
\therefore N & =\left(\frac{71}{7523}\right)^{1 /-0.333}=1.2 \times 10^{6} \text { cycles }
\end{aligned}
$$

Since 2 million cycles represent 2 million $\mathrm{km}$, the predicted distance to failure would therefore be $1.2 \times 106 \mathrm{~km}$. The predicted life correlates very well with the field failures, therefore verifying the FESL method.

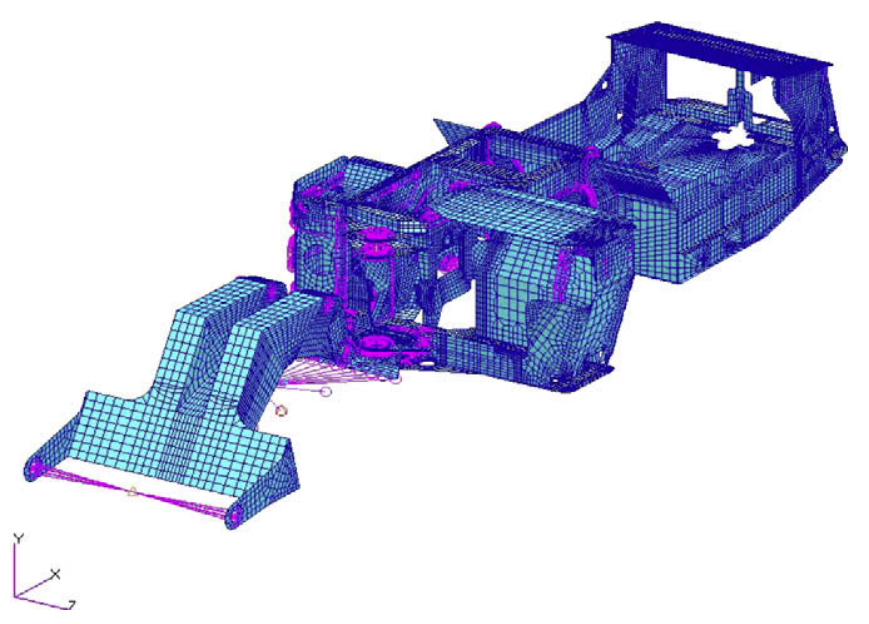

Fig. 10. Finite element model.

\section{Load haul dumper}

\subsection{Problem definition}

Load haul dumpers (LHD) (refer to Fig. 6), are employed in underground mines to load blasted rock at the stope face and transport it to tipping stations from where the product is transported via conveyors. Such vehicles operate in the harshest of road conditions and this, coupled to high dynamic loads induced during loading and dumping, imply fatigue problems. The need for structural design criteria for such vehicles arises from the production requirement for reliable vehicles with predictable lives.

\subsection{Methodology}

- A finite element model of a LHD was generated and used to determine suitable positions where strain gauges could be located to measure the input load responses.

- The vehicle was instrumented with strain gauges, and the strains during the typical operational cycles of the vehicles were recorded.

- The results of these measurements were used to calculate static equivalent fatigue loads, which in turn could be introduced into the finite element model to perform fatigue life predictions on the total vehicle structure.

- Due to the fact that significant fatigue failures have been experienced on the vehicle in operation, it was also possible to verify the methodology, by comparing the predicted failures with actual failures.

\subsection{Instrumentation and measurements}

The vehicles were instrumented with strain gauges, displacement transducers and accelerometers, using a total number of 20 channels. Typical strain gauge positions are depicted in Figs. 7 and 8.

The measurements were performed at platinum mines, during normal operation, typically recording $2 \mathrm{~h}$ of data. The vehicles were operated by regular LHD operators, performing typical tasks. The

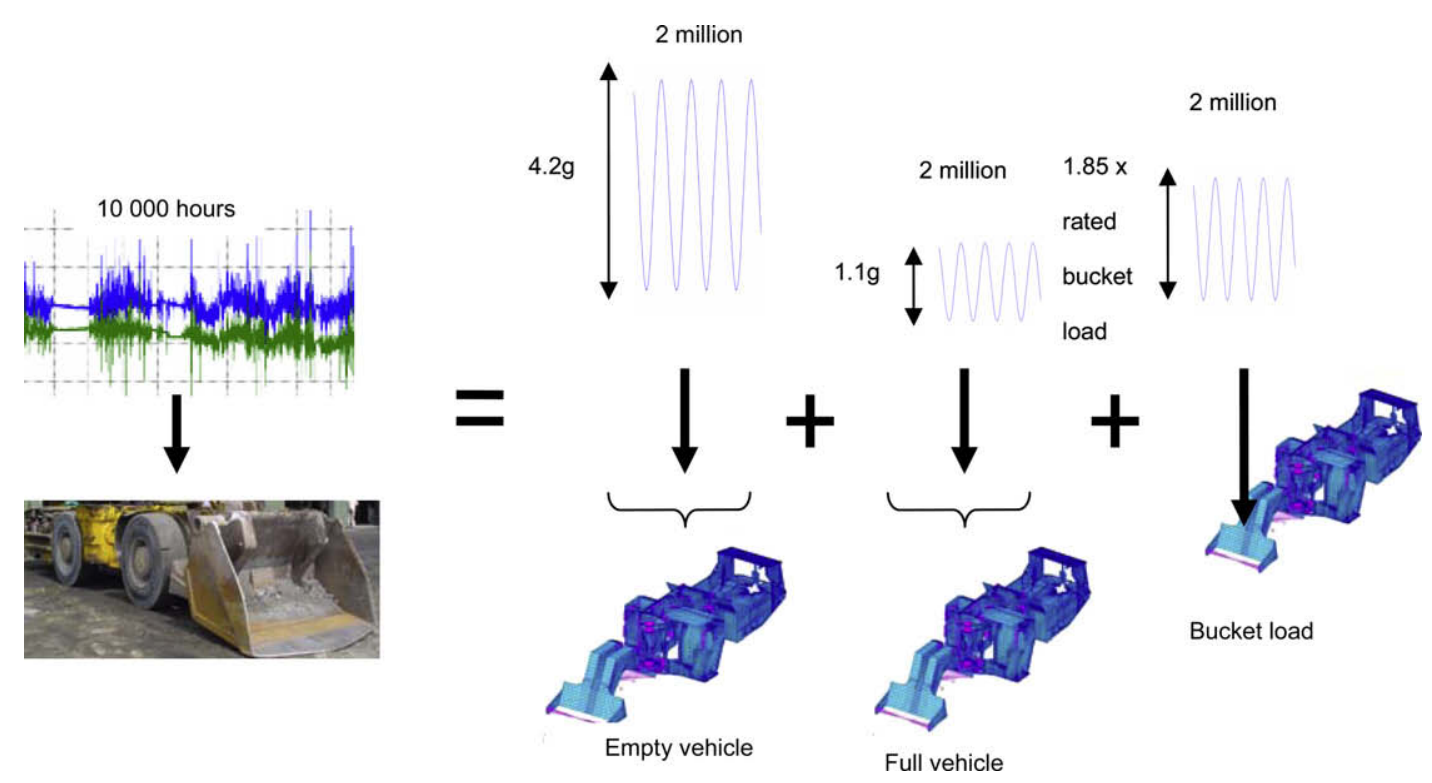

Fig. 11. Equivalent fatigue loading. 
data was recorded with a SOMAT field computer. Typical measurement results are depicted in Fig. 9.

\subsection{Finite element analysis}

\subsubsection{Model}

The geometry and mesh of the vehicle structure were generated in MSC Patran. The model is depicted in Fig. 10. The rear chassis and boom section of the vehicle was modelled. The front chassis was simulated in the model with rigid elements to ensure that the force transfer was correct.

\subsubsection{Constraints and loads}

The model was constrained at the rear wheel axle in the vertical $(Y)$ and lateral $(Z)$ directions to simulate the rear suspension. The model was constrained at the front axle in all three translations and rotation about the longitudinal axis.
The masses of the engine, bucket and front chassis were introduced to model as mass elements with the appropriate centre of gravity positions and masses. Three load cases, each implying a different model, were considered:

- Model A where the bucket is empty, the boom is resting on its stops and inertial loading is applied to simulate empty travelling.

- Model B where the bucket is full (6000 kg), the boom is resting on its stops and inertial loading is applied to simulate full travelling.

- Model C where the boom is lifted and loading is applied on the boom to simulate the effect of forces on the bucket during loading or off-loading.

\subsubsection{Unit load analysis}

It was decided to apply only vertical loading for all three models, since vertical loads would by far represent the largest

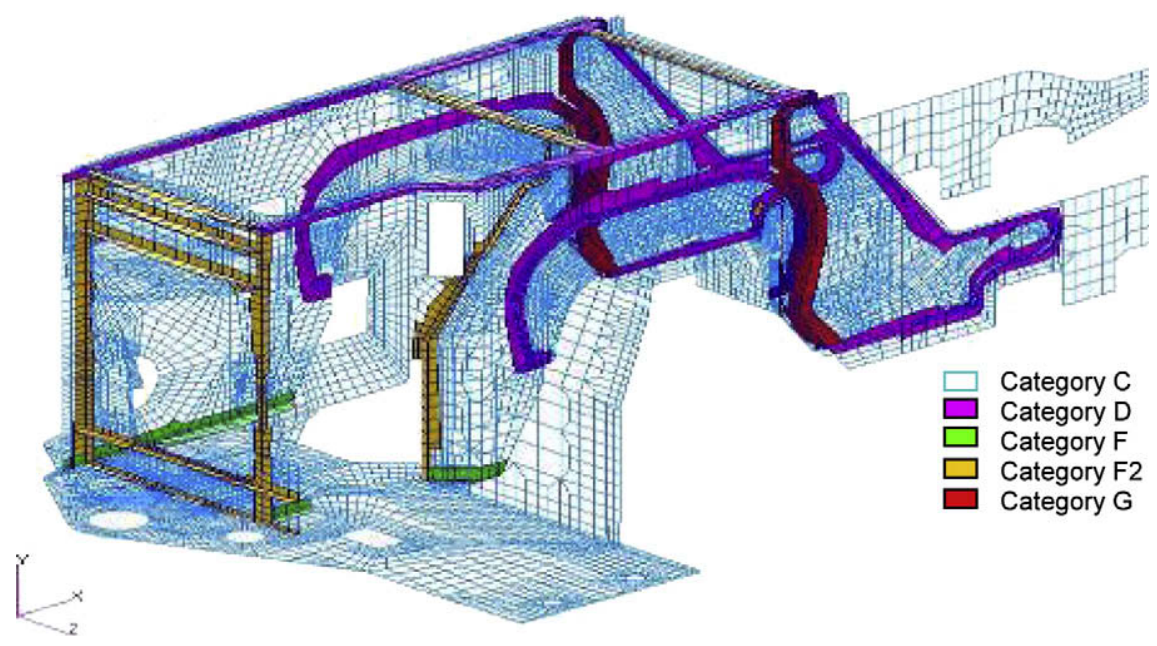

Fig. 12. Weld categories according to BS7608.
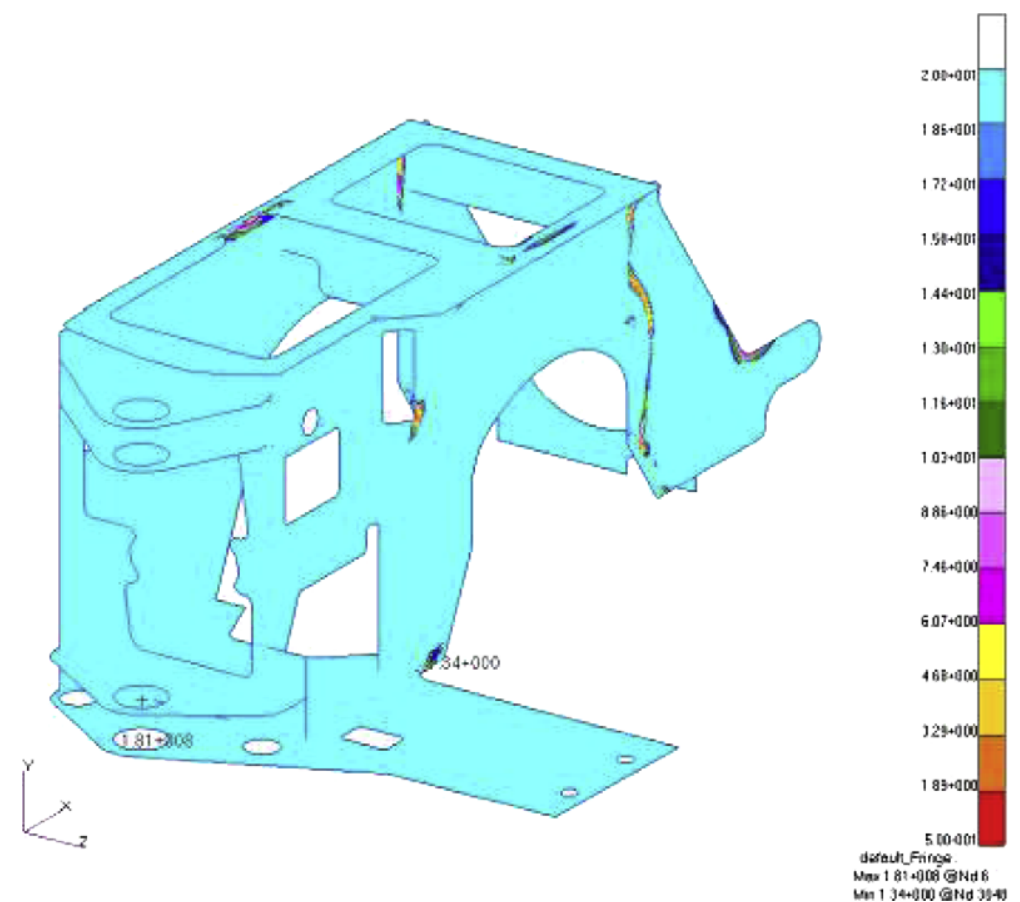

Fig. 13. Fatigue life results for LHD. 
proportion of fatigue damaging loads on the vehicle structure (horizontal loads due to hitting the side walls, ramming the bucket into a pile, braking, turning and accelerating, would occur far less frequently than vertical loads). Again, this assumption was tested by comparing the FESL damages at the unused strain gauge positions, with the actual measured damages. Three strain gauges were therefore chosen in order to solve for the fatigue equivalent static loads (all vertical) for the three models, namely channel numbers 3, 4 and 7. The finite element stress results at each gauge position for $1 \mathrm{~g}$ load applied to each model were as follows:

$$
\left[\begin{array}{lll}
\sigma_{1 \mathrm{~g}, A 3} & \sigma_{1 \mathrm{~g}, B 3} & \sigma_{1 \mathrm{~g}, C 3} \\
\sigma_{1 \mathrm{~g}, A 4} & \sigma_{1 \mathrm{~g}, B 4} & \sigma_{1 \mathrm{~g}, C 4} \\
\sigma_{1 \mathrm{~g}, A 7} & \sigma_{1 \mathrm{~g}, B 7} & \sigma_{1 \mathrm{~g}, C 7}
\end{array}\right]=\left[\begin{array}{ccc}
-3.5 & -12.5 & -12.5 \\
12 & 12 & 4.34 \\
5.8 & 25 & 35
\end{array}\right] \mathrm{MPa}
$$

\subsubsection{Measured damage calculation}

Relative fatigue damages for the measured runs for each of the three chosen channels were calculated. These damages $\left(D_{3}, D_{4}, D_{7}\right)$ were calculated after performing cycle counting (providing $n_{i}$ and $\left.\Delta \sigma_{i}\right)$, using Eq. (3):

$D_{j}=\sum \frac{n_{i}}{N_{i}}=\sum \frac{n_{i}}{\left(\frac{\Delta \sigma_{i}}{S_{f}}\right)^{1 / b}}$

The calculated damages were extrapolated to total damages for a $10000 \mathrm{~h}$ life as follows:

$T D_{j}=D_{j} \times 10000 \mathrm{~h} /$ duration of measurement run (in hours)

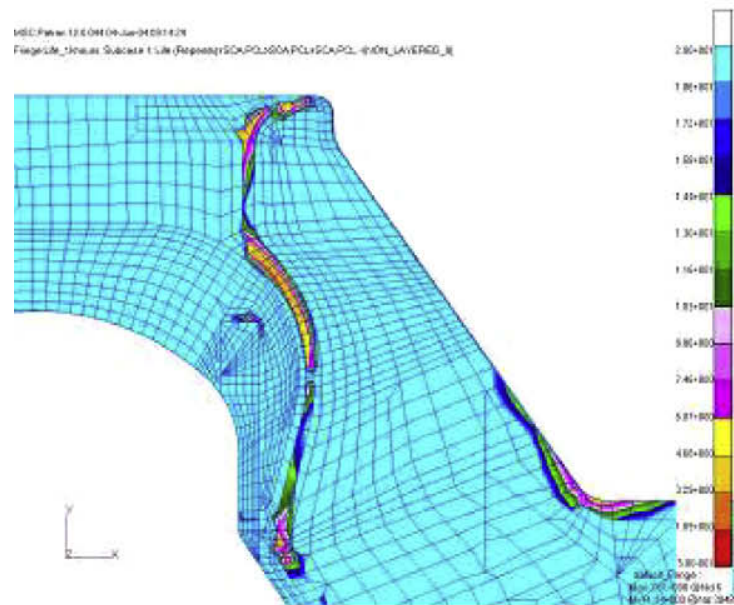

Failure predicted after 3000
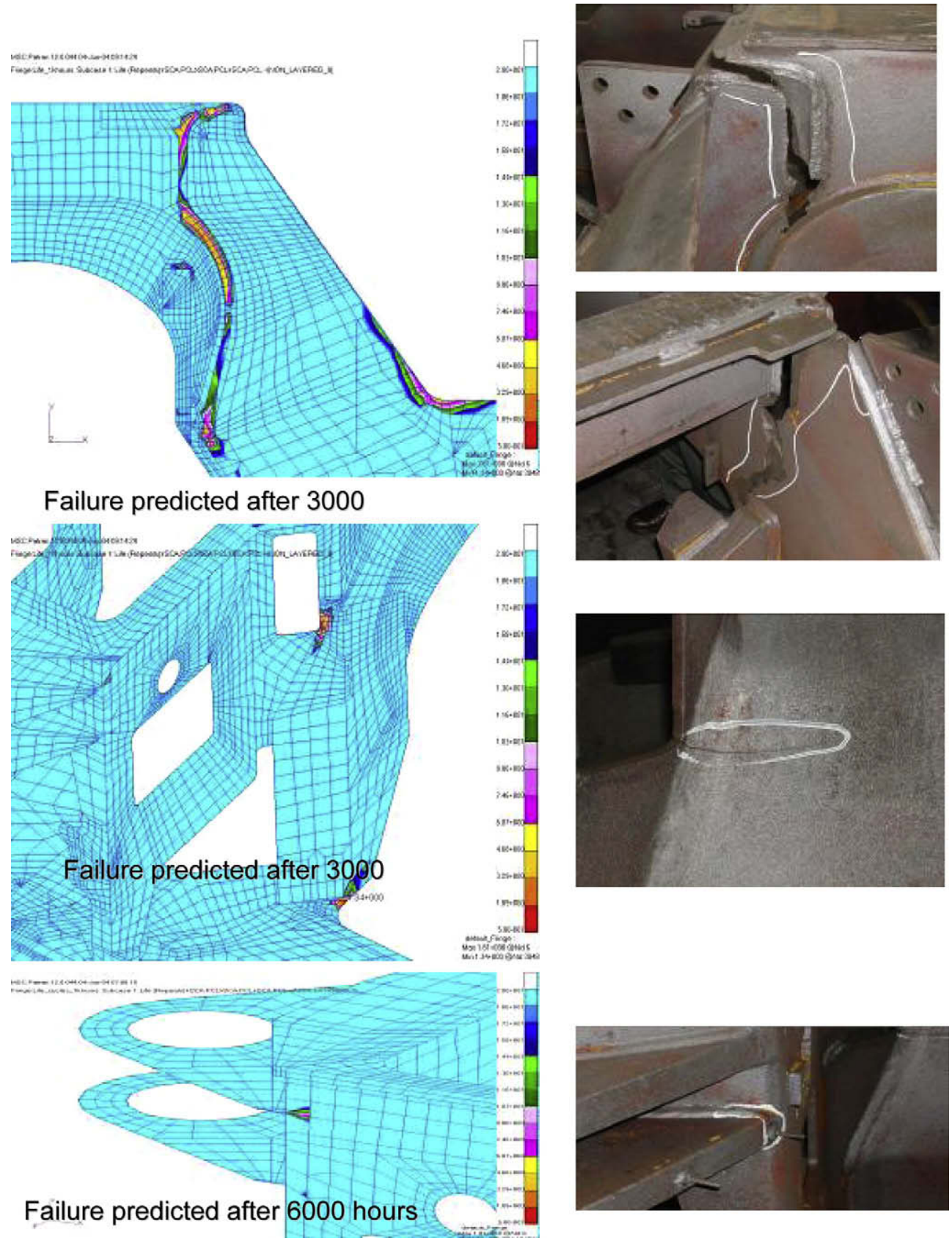

Fig. 14. Correlation of predicted failures and field failures for LHD. 
4.4.5. Fatigue equivalent static load calculation

The process that was followed in this case study to calculate fatigue equivalent static loads, differed from the fuel tanker case study described above in that three finite element models contributed to the total damage estimate. The process was based on summation of damages, since the damages induced in the structure due to stresses on the three different models, are uncoupled (occur separately).

For model $k$ and strain gauge position $j$, the damage $D_{k j}$ induced by stresses (unit load stress $\sigma_{k j}$ for model $k$ at gauge $j$ from Eq. (8), multiplied by the to-be-determined fatigue equivalent static load $\mathrm{FESL}_{k}$ ), may be calculated:

$D_{k j}=\frac{n}{\left(\frac{\sigma_{k j} \times \mathrm{FESL}_{k}}{S_{f}}\right)^{1 / b}}$

The total damage at gauge position $j$ must then be equal to the summation of the damages $D_{k j}$ for $k=A, B, C$ :

$$
\frac{2 \times 10^{6}}{\left(\frac{\operatorname{FESL}_{A} \sigma_{A j}}{S_{f}}\right)^{-3}}+\frac{2 \times 10^{6}}{\left(\frac{\mathrm{FESL}_{B} \sigma_{B j}}{S_{f}}\right)^{-3}}+\frac{2 \times 10^{6}}{\left(\frac{\mathrm{FESL}_{C} \sigma_{G j}}{S_{f}}\right)^{-3}}=T D_{j}
$$

Three such equations exist, for each of the three channels $(j=3,4$, 7 ). From these three equations, the three unknown fatigue equivalent static loads could be solved as $\left(\mathrm{FESL}_{A}=4.2 \mathrm{~g}, \mathrm{FESL}_{B}=1.1 \mathrm{~g}\right.$, $\mathrm{FESL}_{C}=1.85 \mathrm{~g}$ ). When the above loads are applied to the three models, the stresses that are calculated are then used as stress ranges, applied 2 million times in a $10000 \mathrm{~h}$ life, and by using the appropriate $S N$ curves, damages at any critical position may be calculated by adding the damages for the three models, as depicted in Fig. 11.

\subsubsection{Fatigue life prediction}

All the critical connections in the vehicle structure in the finite element model were divided into different groups, which correspond with the categories described in ECCS [8]. The parent metal, for example, was grouped as a category $\mathrm{C}$, and a full penetration fillet weld as a category $\mathrm{D}$, etc. The weld categories as chosen for the vehicle are depicted in Fig. 12.

Using MSC FATIGUE solver, the stress results from the load factors were used to calculate the damage for the whole finite element model, using different $S N$ curves for each category. The result of this analysis would be the damage of one cycle for the whole model for each load case.

The damages for the three load cases can then be summed, and then inversed again to give the number of cycles the structure will survive for the combined load case. As mentioned, 2 million of these cycles correspond to a life of $10000 \mathrm{~h}$. The result of this analysis is depicted in Fig. 13.

\subsubsection{Correlation with field failures}

Cracks were found on the chassis of a vehicle that was approximately 6000 h old. Photographs of these cracks, together with the corresponding fatigue life prediction contour plots, are depicted in Fig. 14. Adequate correlation was achieved.

\section{Conclusions}

A fatigue equivalent static loads (FESL) methodology was presented, where fatigue load requirements are derived from measurements as quasi-static g-loads, the responses to which are considered as stress ranges applied a said number of times during the lifetime of the structure.

The application of the method was demonstrated using two case studies, namely a road tanker and a load haul dumper. In both cases it was possible to obtain adequately accurate fatigue life prediction results, based on limited measurements, using only a single strain gauge in the one case study and three in the other, to derive simplified loading, serving as inputs to static finite element analyses and a stress-life approach to fatigue damage calculations, with material properties available in design codes.

\section{References}

[1] Pettersson G. Fatigue analysis of a welded component based on different methods. Weld World 2002;46(9/10).

[2] Huang L, Agrawal H, Borowski V. Durability analysis of vehicle body structure using modal transient methods. In: Proceedings of the international modal analysis conference IMAC, V1; 1997.

[3] Berger C, Eulitz K-G, Heuler P, Kotte K-L, Naundorf H, Schuetz W, et al. Betriebsfestigkeit in Germany - an overview. Int J Fatigue 2002;24(6).

[4] Ryu J, Kim H, Wang S. A method of improving dynamic stress computation for fatigue life prediction of vehicle structures. SAE 971534; 1997.

[5] Conle FA, Chu CC. Fatigue analysis and the local stress-strain approach in complex vehicular structures. Int J Fatigue 1998;19(1).

[6] Bannantine JA, Comer JJ, Handrock JL. Fundamentals of metal fatigue analysis. Prentice-Hall; 1990.

[7] Gurney TR. Fatigue design rules for welded steel joints. Weld Inst Res Bull $1976 ; 17$.

[8] European Convention for Constructional Steelwork (ECCS). Recommendations for the fatigue design of steel structures; 1985.

[9] British Standards Institution. Structural use of aluminium. BS 8118. Part 1; 1991.

[10] Wannenburg J. The probabilistic establishment of durability requirements based on field failure data. Environ Eng 1993;20(9).

[11] ASTM (American Society for Testing of Materials) E 1049-85. Standard practices for cycle counting in fatigue analysis; 1989.

[12] Miner MA. Cumulative damage in fatigue. J Appl Mech, Trans ASME $1945 ; 67$. 